\title{
Impact of Hormonal Treatment in Patients with Metastatic Prostatic Carcinoma (Retrospective Study)
}

\author{
Haytham Mohammed ${ }^{1, *}$ MSc, Wael El-Sheshtawy ${ }^{1}$ MD, Mohsen Zikri ${ }^{1}$ MD
}

\author{
*Corresponding Author: \\ Haytham Mohammed \\ hythamsalama@gmail.com
}

\section{Received for publication January 8, 2020; accepted January 24, 2020; published on line January 26, 2020.}

\section{Copyright 2020 The Authors published by Al-Azhar University, Faculty of Medicine, Cairo, Egypt. All rights reserved. This an open- access article distributed under the legal terms, where it is permissible to download and share the work provided it is properly cited. The work cannot be changed in anyway or used commercially. \\ doi:10.21608/aimj.2020.22125. 1060 \\ ${ }^{1}$ Clinical Oncology \& Nuclear Medicine Department, Faculty of Medicine, Al-Azhar \\ University, Cairo Egypt.}

\begin{abstract}
Background: worldwide, prostate cancer is the second most common cancer and the fifth leading cause of death from cancer in men. Objective: is to study the impact of hormonal treatment in patients with metastatic prostatic carcinoma.

Subject and Methods: This retrospective study included all patients diagnosed with metastatic prostate cancer, treated at our center between the year 2007 and 2016, data of patients included was reviewed from the charts and analyzed for outcome.

Results: the study included 39 patients, 21 patients (52.6\%) had subjected to primary bilateral orchiectomy as first line management while (18) patients (47.4\%) received ADT. Median PFS for 1st line hormonal treatment was 18.4 months and Median OS were 25.5 months. Patients with good performance (PS) status 0- II had longer overall survival than those with PS III (37 vs. 18 months) with significant Pvalue (0.05).Patients with base line PSA around $70 \mathrm{ng} / \mathrm{ml}$ had longer OS (23 vs. 11 months) with significant P- value $(0.05)$.

Conclusions: Outcome of metastatic prostate cancer patients who have been treated at our center significantly affected by PS at presentation and baseline PSA level. However the absolute survival number needs to be improved by implementation of newly approved drugs in the 1 st and 2 nd lines, that isn't currently available in our center.
\end{abstract}

Keywords: prostatic carcinoma; Hormonal therapy; Metastatic; ADT and Casterization.

\section{INTRODUCTION}

Worldwide, prostate cancer is the second most common cancer and the fifth leading cause of death from cancer in men, with an estimated 164.690 new case diagnosed in 2018 at united states, mortality rate from prostate cancer is also estimated to be about $9 \%$ of male cancer death in $2018 .^{1}$

About $4 \%$ of prostate cancer patients presented with metastatic disease on initial diagnosis, and about onethird of localized prostate cancer patients experience disease progression during the course of treatment. ${ }^{2}$

Most of prostate cancers that diagnosed with localized disease are considered less aggressive malignancy because of their indolent course; nonetheless, metastatic prostate cancer is still lethal. The 5-year survival rate approaches $100 \%$ for low risk patients with localized disease, but once the metastases occurs the disease become practically incurable and 5 years survival declined to $28 \%{ }^{3}$

Since the usage of prostate-specific antigen (PSA) tests increased as screening purpose, early detection of prostate cancer has increased, and death from
Authorship: All authors have a substantial contributions to the article.

Disclosure: The authors have no financial interest to declare in relation to the content of this article. The Article Processing Charge was paid for by the authors.

prostate cancer has been gradually reduced over time. However, the concerns about the over diagnosis and over treatment have increased. As a result, in 2008 and 2012 United States Prevention Services Task Force (USPSTF) recommended against routine PSA screening. After this, a decline in the incidence of localized prostate cancer has been reported, and these have been a raising concern for worsening of prostate cancer-specific survival. Based on some recent studies, intermediate- or high-risk prostate cancer reported to increase by $6 \%$ from 2011 to 2013 , which support this concern. In addition, metastatic prostate cancer has been increased from 2004 to $2013 .^{4,5}$

Androgen suppression using bilateral orchiectomy or luteinizing hormone releasing hormone (LHRH) agonist/antagonist should be first-line treatment along with short-course anti-androgen to prevent disease flare at starting treatment with LHRH. ${ }^{6}$

Androgen Deprivation Therapy (ADT) is associated with a wide range of side effects that can 
significantly impair quality of life, Important and/or frequent side effects include loss of lean body mass, increased body fat, decreased muscle strength, decrease bone mineral density and sexual dysfunction. $^{7}$ The treatment of metastatic cancer prostate has significantly changed over the past 5 years. Since 2015, two clinical trials, CHAARTED and STAMPEDE arm C, demonstrated that up-front docetaxel plus ADT improves overall survival (OS). ${ }^{8,9}$

Then, in 2017, two clinical trials, LATITUDE and STAMPEDE arm G, showed that up-front abiraterone plus prednisone plus ADT improves OS to a similar degree as docetaxel plus ADT did..$^{10,11}$

\section{MATERIAL AND METHODS}

This retrospective study included all patients diagnosed with metastatic prostate cancer, registered and treated at our clinical Oncology Department, AlHussein University hospital in the period between January 2007 and December 2016. Charts of included patients had been reviewed and relevant data were collected and statistically analyzed.

The study Included male patient regardless of age who have had pathologically proven prostate cancer, radiological documented distant metastasis and performance status ranging from 0 -III $\mathrm{WHO}$; on the other hand patients who have secondary malignancy, performance status IV or received any kind of treatment outside our facility were excluded from the study.

The relevant data collected in the study included; patient related data (age, sex, family history and comorbidity); disease related data (baseline and follow-up PSA, Gleason score, tumor grade, number of biopsied cores, number of positive cores, percentage of positive disease in each core and finally, local and systemic extent of the disease); and treatment related data including type, toxicity, response and progression free survival related to each line of therapy.

Patients were classified based on metastasis load into two categories; high volume disease and low volume disease according to presence or absence of visceral metastasis and, sit and number of bone lesions, as following; high volume disease defined as the presence of visceral metastases or at least four bone lesions with one or more beyond the vertebral bodies and pelvis and low volume disease include those who had no visceral metastasis and less than three sites of bone metastasis.

Data were coded and entered using the statistical package SPSS version 23. Data was summarized using mean, standard deviation, median, minimum and maximum for quantitative variables and frequencies (number of cases) and relative frequencies (percentages) for categorical variables. Survival interval conspired as time between the date of histological diagnosis and the date of the last follow-up (for censored observations) or the date of death (for uncensored observations), while progression free interval was considered as time between date of the first treatment and the date of the last follow-up (for censored observations) or; date of death or disease progression whichever happen first (for uncensored observations). One-sided log-rank of Kaplan-Meier survival estimates was used for statistical analysis of overall survival and progression free survival, while the unpaired $\mathrm{T}$ test and one-way ANOVA test were used in the univariate analysis of the variables. Results of P-value less than 0.05 were considered statistically significant.

\section{ETHICAL APPROVAL:}

The current investigation had been approved by the ethical committee, Faculty of Medicine, Al-Azhar University, Cairo, Egypt, before the start of this study.

\section{RESULTS}

After reviewing the charts of 100 patients who reported to have prostate cancer in our archive, 39 patients was found to have metastatic prostate cancer (illegible for the study), among these illegible patients; mean age was 66.1 years (range 51:78); 19 patients $(47.4 \%)$ were cigarette smoker and 20 patients $(52.6 \%)$ were non-smokers; family history of malignancy was reported by 14 patients $(34.2 \%)$; most of the patients was presented with WHO performance status (PS) II, 18 patients $(47.4 \%)$, while 11 patients $(26.4 \%)$, and 10 patients $(26.3 \%)$ were having PS 0-I and PS III-IV respectively; the most common presenting symptoms were urinationrelated symptoms in 24 patients $(61.6 \%)$ followed by boney aches in 15 patients $(38.4 .8 \%)$. (Table 1 )

All patients were having prostate adenocarcinoma on TRUS core needle biopsy, the median number of biopsied cores was 6 (range $6: 12$ ), while the median number of positive cores was 4 (range 3-8), median percentage of malignancy in each cores was $70 \%$ (range $25: 100$ ); Gleason score (GS) $\leq 6$ was reported in four patients $(7.9 \%)$, while GS 7 and GS $8-10$ were reported in 15 patients $(39.5 \%)$ and 20 patients $(52.6 \%)$ respectively; all patients were having bone metastasis, of them 30 patients $(76.3 \%)$ had high volume disease and 9 patients $(23.7 \%)$ had low volume disease, while 15 patients $(38.3 \%)$ was having visceral metastasis, median baseline PSA level was $70 \mathrm{ng} / \mathrm{ml}$ (range 10:1850). (Table 1)

Bilateral orchiectomy was first line treatment in 21 patients $(52.6 \%)$, while 18 patients $(47.4 \%)$ received ADT as primary treatment, in 14 patients (33.8\%) ADT was LHRH agonist + bicultamide and LHRH agonist + flutamide acetate in four patient $(22.2 \%)$; biochemical response to primary hormonal treatment was reported in $70 \%$ of patients; the most noticed treatment related toxicity were mild anemia in 7 patients and osteoporosis in 4 patients while grade 3-4 toxicity was not reported. (Table 2,3 )

palliative radiotherapy was used at presentation in 8 patients who presented to us with cord compression , with subjective improvement in lower limb weakness and motor power, while used during later time in 30 patients who developed bone pain as palliative treatment of pain and tenderness and in one patient with brain metastasis, Second line hormonal treatment in 21 patients $(52.6 \%)$ as following, 9 
patients $(22.5 \%)$ received LHRH agonist gasroline acetate + bicultamide, 10 patients $(25 \%)$ received flutamide, one patient $(2.5 \%)$ received surgical casterization + biclutamide and 1patient $(2.5 \%)$ received biclutamide with doubled dosage , With biochemical response in $(57 \%)$ of patients while

\begin{tabular}{|c|c|c|}
\hline & No. & $(\%)$ \\
\hline \multicolumn{3}{|l|}{ Age } \\
\hline Mean \pm SD & $66.1 \pm 8.4$ & \\
\hline Minimum & 51 & \\
\hline Maximum & 78 & \\
\hline \multicolumn{3}{|l|}{ Grade } \\
\hline 2 & 14 & $28.9 \%$ \\
\hline 3 & 25 & $63.2 \%$ \\
\hline Family history (positive) & 14 & $34.2 \%$ \\
\hline Smoking (Positive) & 19 & $47.4 \%$ \\
\hline \multicolumn{3}{|l|}{ Co- morbidities } \\
\hline DM (positive) & 12 & $31.6 \%$ \\
\hline HTN (positive) & 20 & $52.6 \%$ \\
\hline \multicolumn{3}{|l|}{ Performance status ECOG score } \\
\hline $0-1$ & 11 & $26.4 \%$ \\
\hline 2 & 18 & $47.4 \%$ \\
\hline 3 & 10 & $26.3 \%$ \\
\hline \multicolumn{3}{|l|}{ Presentation } \\
\hline Prostatism & 19 & $50 \%$ \\
\hline Bony aches & 15 & $44.8 \%$ \\
\hline Hematouria & 3 & $5.3 \%$ \\
\hline Less than70 PSA & 19 & $47.4 \%$ \\
\hline More than 70 PSA & 20 & $52.6 \%$ \\
\hline \multicolumn{3}{|l|}{ Site of metastasis } \\
\hline low volume bone metastasis & 9 & $23.7 \%$ \\
\hline High volume bone metastasis & 30 & $76.3 \%$ \\
\hline Visceral mets & 15 & 38.3 \\
\hline \multicolumn{3}{|l|}{ First line treatment } \\
\hline Medical Hormonal treatment & 18 & $47.4 \%$ \\
\hline Surgical Hormonal treatment & 21 & $52.6 \%$ \\
\hline \multicolumn{3}{|l|}{ Gleason score } \\
\hline$\leq 6$ & 4 & 7.9 \\
\hline 7 & 15 & 39.5 \\
\hline $8-10$ & 20 & 52.6 \\
\hline
\end{tabular}

Table 1: Patient characteristics

\begin{tabular}{|c|c|c|}
\hline & $\begin{array}{c}\text { Frequency } \\
\text { n(39) }\end{array}$ & Percentage\% \\
\hline Surgical castration & 21 & $52.6 \%$ \\
\hline ADT alone & 18 & $47.4 \%$ \\
\hline
\end{tabular}

Table 2 :First line management 


\begin{tabular}{|c|c|c|c|}
\hline \multicolumn{2}{|c|}{} & Total no (39) & $\%$ \\
\hline \multirow{3}{*}{ First line hormonal } & Biclutamide + Goserline acetate & 14 & $33.8 \%$ \\
\cline { 2 - 4 } & Flutamide + Goserline acetate & 4 & $10.2 \%$ \\
\cline { 2 - 4 } & Surgical/l castration & 21 & $53.8 \%$ \\
\hline
\end{tabular}

Table 3 : Type of Hormonal treatment in 1st line

\begin{tabular}{|l|c|c|c|}
\hline \multirow{2}{*}{\begin{tabular}{c}
$*$ \\
\multirow{2}{*}{$\begin{array}{c}\text { Palliative radiotherapy } \\
(\mathrm{n}=39)\end{array}$} \\
\cline { 2 - 4 }
\end{tabular}} & No Rth received & 10 & $25.3 \%$ \\
\cline { 2 - 4 } & Bone mets & 28 & $73.7 \%$ \\
\hline
\end{tabular}

Table 4 : Palliative radiotherapy

After a median follow up period four years, median PFS was (18.4) months and one year PFS was reported in about $(70 \%)$ of patients after $1^{\text {st }}$ line hormonal treatment. (Figure 1)

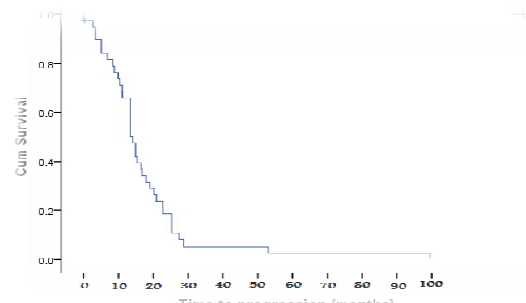

Fig. 1: Represent the progression free survival in all eligible cases

Median OS was (25.5) range months and 1year OS was reported in ( $83 \%$ ) Of studied cases. (Figure 2)

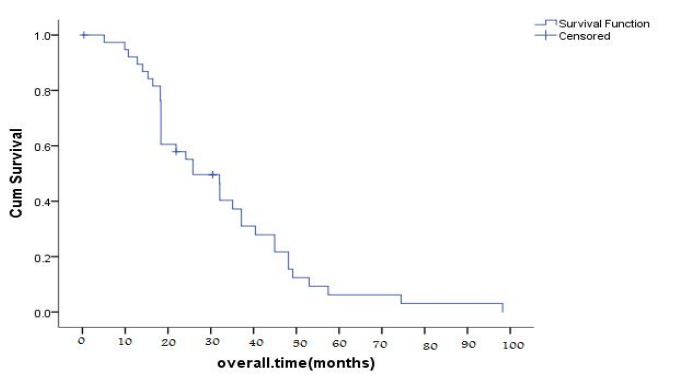

Fig. 2: Represent the overall survival in all eligible cases several factors that could affect metastatic patients who received hormonal treatment had been studied in relation to both PFS and OS . only two factors had significant impact on overall survival; performance status and PSA value at presentation. (Figure 3) (Table 5,6)

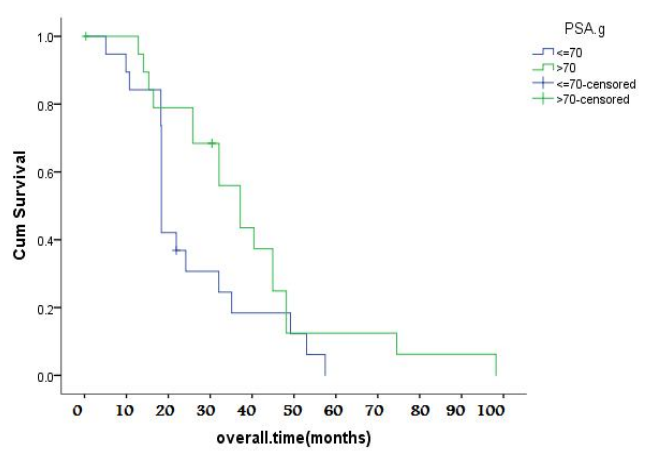

Fig. 3: Represent effect of PSA on overall survival in all eligible cases 


\begin{tabular}{|c|c|c|c|c|c|c|}
\hline \multirow{2}{*}{\multicolumn{2}{|c|}{ All parameters }} & \multirow{3}{*}{$\begin{array}{c}\text { No. (39) } \\
21 \\
\end{array}$} & \multirow{3}{*}{$\begin{array}{c}\text { Median } \\
31.1 \\
\end{array}$} & \multicolumn{2}{|c|}{ C.I. $95 \%$} & \multirow{4}{*}{$\begin{array}{c}\text { P-value } \\
0.256\end{array}$} \\
\hline & & & & Lower & Upper & \\
\hline \multirow{2}{*}{ Age (years) } & $\leq 68$ & & & 33.8 & 38.3 & \\
\hline & $>68$ & 18 & 21.0 & 19.7 & 22.2 & \\
\hline \multirow{2}{*}{ Smoking } & No & 19 & 25.5 & 21.8 & 29.2 & \multirow{2}{*}{0.079} \\
\hline & Yes & 20 & 34.3 & 17.8 & 50.6 & \\
\hline \multirow{3}{*}{$\begin{array}{c}\text { Performance } \\
\text { status }\end{array}$} & $0 . \mathrm{I}$ & 11 & 37 & 31.53 & 42.47 & \multirow{3}{*}{$0.05(\mathrm{~S})$} \\
\hline & II & 18 & 24 & 17.56 & 30.44 & \\
\hline & III & 10 & 18.1 & 16.7 & 19.4 & \\
\hline \multirow{2}{*}{ DM } & No & 27 & 21.0 & 18.8 & 23.8 & \multirow{2}{*}{0.161} \\
\hline & Yes & 12 & 31.0 & 22.5 & 39.3 & \\
\hline \multirow{2}{*}{ HTN } & No & 17 & 25.5 & 18.3 & 32.6 & \multirow{2}{*}{0.629} \\
\hline & Yes & 22 & 29.2 & 18.2 & 40.3 & \\
\hline \multirow{3}{*}{ Gleason score } & 7 & 3 & 38.9 & $\cdots$ & 38.9 & \multirow{3}{*}{0.951} \\
\hline & 6 & 17 & 29.3 & 22.8) & 35.9 & \\
\hline & 7 & 19 & 21.0 & $(19.6$ & 22.3 & \\
\hline \multirow{2}{*}{ Bone scan } & Low & 9 & 25.5 & $\cdots$ & 25.5 & \multirow{2}{*}{0.780} \\
\hline & High & 30 & 24.5 & 16.2 & 32.8 & \\
\hline \multirow[b]{2}{*}{ Bone modifying agents } & Free & 25 & 24.5 & 19.4 & 29.6 & \multirow[b]{2}{*}{0.926} \\
\hline & $\begin{array}{c}\text { Zolidronic } \\
\text { acid }\end{array}$ & 14 & 29.2 & 12.9 & 45.6 & \\
\hline \multirow{2}{*}{ Grade } & II & 14 & 29.3 & 22.4 & 36.1 & \multirow{2}{*}{0.976} \\
\hline & III & 25 & 21.0 & 18.9 & 23.1 & \\
\hline \multirow{2}{*}{ PSA } & $\leq 70$ & 19 & 22.3 & 16.6 & 11.1 & \multirow{2}{*}{0.052} \\
\hline & $>70$ & 20 & 11.0 & 10.9 & 38.0 & \\
\hline \multirow{2}{*}{ Positivity } & $\leq 50$ & 19 & 25.5 & 16.9 & 34.0 & \multirow{2}{*}{0.786} \\
\hline & $>50$ & 20 & 22.0 & 15.9 & 16.0 & \\
\hline \multirow{2}{*}{ Casterization } & Surgical & 21 & 29.3 & 23.6 & 34.8 & \multirow{2}{*}{0.140} \\
\hline & Treatment & 18 & 22.0 & 17.7 & 24.3 & \\
\hline
\end{tabular}

Table 5: Correlation between overall survival with different factors 


\begin{tabular}{|c|c|c|c|c|c|c|}
\hline \multirow{2}{*}{\multicolumn{2}{|c|}{ All parameters }} & \multirow{3}{*}{$\begin{array}{c}\text { No. (39) } \\
21\end{array}$} & \multirow{3}{*}{$\begin{array}{c}\text { Median } \\
18.9\end{array}$} & \multicolumn{2}{|c|}{ C.I. $95 \%$} & \multirow{2}{*}{ P-value } \\
\hline & & & & Lower & Upper & \\
\hline \multirow{2}{*}{ Age (years) } & $\leq 68$ & & & 15.1 & 22.8 & \multirow{2}{*}{0.710} \\
\hline & $>68$ & 18 & 18.1 & 16.2 & 19.9 & \\
\hline \multirow{2}{*}{ Smoking } & No & 19 & 20.1 & 16.3 & 23.8 & \multirow{2}{*}{0.205} \\
\hline & Yes & 20 & 16.2 & 14.2 & 18.1 & \\
\hline \multirow{3}{*}{$\begin{array}{c}\text { Performance } \\
\text { status }\end{array}$} & $0 . \mathrm{I}$ & 11 & 18 & 0.76 & 16.52 & \multirow{3}{*}{0.302} \\
\hline & II & 18 & 16 & 2.27 & 11.56 & \\
\hline & III & 10 & 6 & 4.00 & 0.00 & \\
\hline \multirow{2}{*}{ DM } & No & 27 & 18.1 & 16.5 & 19.6 & \multirow{2}{*}{0.288} \\
\hline & Yes & 12 & 19.2 & 16.1 & 22.3 & \\
\hline \multirow{2}{*}{ HTN } & No & 17 & 18.9 & 17.1 & 20.8 & \multirow{2}{*}{0.255} \\
\hline & Yes & 22 & 18.1 & 16.0 & 20.1 & \\
\hline \multirow{3}{*}{ Gleason score } & 7 & 3 & 18.9 & $\cdots$ & 18.9 & \multirow{3}{*}{0.951} \\
\hline & 6 & 17 & 22.4 & 18.4 & 24.4 & \\
\hline & 7 & 19 & 18.1 & 17.2 & 18.9 & \\
\hline \multirow{2}{*}{ Bone scan } & low & 9 & 22.5 & 20.0 & 24.9 & \multirow{2}{*}{0.233} \\
\hline & High & 30 & 18.1 & 16.7 & 19.4 & \\
\hline \multirow{2}{*}{ Bone modifying agents } & Free & 25 & 18.1 & 16.9 & 24.9 & \multirow{2}{*}{0.823} \\
\hline & Zometa & 14 & 18.9 & 14.4 & 23.4 & \\
\hline
\end{tabular}

Table 6: Correlation between PFS and different patient characteristics

\section{DISCUSSION}

Prostate cancer account for $2.5 \%$ of all cancers presented to our department from the period between January 2007 and December 2016 Our study is not consistent with the published data in our country according to the results of the National PopulationBased Cancer Registry Program (NCRP) In Egypt, prostate cancer is the $6^{\text {th }}$ most common male cancer it comprised $4.7 \%$ of malignancies in males. ${ }^{12}$

Treatment options include active surveillance, surgery (open, laparoscopic, or robotic-assisted), external beam radiation, or brachy therapy. Hormonal therapy may be used along with surgery or radiation therapy in more advanced cases. More advanced disease is treated with hormonal therapy, chemotherapy, radiation therapy, and/or other treatments. $^{13}$
In our retrospective study, we examined individual and clinico-epidemiological factors contributing to overall PCa survival, PFS in prostate cancer patients at the archive of Clinical Oncology and Nuclear Medicine Department, Al-Hussein Hospital, AlAzhar University.

The study population number was 39 male patients. The mean age of the studied population was 66 years (range 51:78) consistent with mean age worldwide which is 67 years. ${ }^{14}$

In our study OS was statistically insignificant with age although patients $<68$ years had a median OS of 21 (95\% CI 19.7-22.2) months while those $\geq 68$ years had a median OS of 31 (95\% CI 33.8-38.3) months $\mathrm{P}=0.256$. 
Much co-morbidity were associated with prostate cancer seen in higher age population. Most of the patients were older than 65 years old. In our study, the most relevant co-morbidity among studied population was cardiovascular disease in which $52.6 \%$ of the patients complaining of hypertension and $7.9 \%$ had IHD. Diabetes mellitus (DM) was found in $31.6 \%$ of patients.

Similarly, Spanish data reported that of all comorbidities $48.15 \%$ of the patients complained of cardiovascular diseases and $14.41 \%$ complained of Diabetes mellitus. Much co-morbidity were associated with prostate cancer seen in higher age population. ${ }^{15}$

In the United States, most prostate cancers patients are diagnosed because of screening; they are mostly asymptomatic at time of diagnosis. With a small percentage having local symptoms, which usually indicates locally advanced disease. While, in our study, most of patients presented with variable symptoms; the most common was prostatism in $61.6 \%$ of patients including irritative and obstructive urinary symptoms and bony aches in $38.8 \%$. The lack of awareness and absence of a screening program led to the late presentation of most our patients 16 .

They found that among the 6,457 men diagnosed with prostate cancer in Florida during 2001-2007, about $12.70 \%$ were diagnosed with advanced stage of prostate cancer. While in our study $54 \%$ of patients had local disease and $46 \%$ had distant stage. The lack of awareness and the late presentation of the patient consistent with the fact that the study population from a single tertiary referral unit are the reasons of our results and likely due to absence of co-operation between us and urological department so they accept patients with localized prostate cancer that will underwent surgery and keep patients under follow up and refer them to us when become metastatic so this justify high percentage of metastatic patients. ${ }^{16}$

In our study patients treated with ADT demonstrated that defined LV patients had a longer overall survival (25.5months) and progression free survival (22.5 months) compared to patients with HV disease OS (24.5 months) and PFS (18.1 months) which are consistent with those of the post-hoc analysis of the CHAARTED trial and of the CHAARTED-GETUGAFU15 combined study. ${ }^{16}$

Worldwide Median OS was 42.1 months and median failure-free survival was 11.2 months and the superiority of their results as a result regular follow up to patients under study. ${ }^{17}$

While In our study, initially metastatic prostate cancer patients had median overall survival of 25.5 months (95\% CI 20.3-30.6) and the median PFS was found to be 18.4 months (95\% CI 16.8-19. 9) which was statistically insignificant. Our results could be explained by the heterogeneous population in our study and the lack of regular follow up by our patients. This may due to lack of new line of treatment that not financially supported from ministry of health which make us in circle of traditional line of treatment which may reflect a much better survival estimated in western countries.

In our study ADT either medical or surgical casterization was the first line treatment. Patients subjected to surgical casterization by bilateral orchiectomy or received hormonal treatment by luteinizing hormone-releasing hormone (LHRH) agonists such as gosereline and anti-androgen such as biclutamide or flutamide which similar to data published. ${ }^{18}$

After progression another line of hormonal treatment was used either surgical casterizatin or medically by anti-androgens or increasing the dose of antiandrogen. In patients whose sill developing progression chemotherapy used and only 6 patients $(15 \%)$ received dosetaxel from 6 to 10 cycles with PFS 6 months range from $(3-11)$ months which similar to data published TAX 327 study by. ${ }^{19}$

But Recently, Chaarted and Stampede studies demonstrated a survival benefit for men with metastatic hormone-sensitive PC (mHSPC) treated with docetaxel plus ADT as first line. Results of the CHAARTED trial were presented in 2014 and published in 2015. Median OS was significantly improved in the ADT plus D arm (57.6 vs $44.0 \mathrm{~ms}$; HR: $0.61 ; \mathrm{p}<0.001)^{8,}$

In order to account for limitations, other than the inherent retrospective nature of the current study, a relatively short follow-up exists considering the long natural history of prostate cancer and lack of usage of the current trends in therapy are evident. However, it remains a viable report of management of this disease even if at a single institutional level.

\section{CONCLUSION}

Outcome of metastatic prostate cancer patients who have been treated at our center significantly affected by PS at presentation and baseline PSA level, however the absolute survival number needs to be improved by implementation of newly approved drugs in the $1^{\text {st }}$ and $2^{\text {nd }}$ lines, that isn't currently available in our center.

\section{REFERENCES}

1. Seigel L, Miller D and Jemale A. Cancer statestics, 2016. CA cancer J Clinic. 2018:68:730.

2. David N, Spears R, Clarke W, et al. Survival with newly diagnosed metastatic prostate cancer in the "Docetaxel Era": data from 917 patients in the control arm of the STAMPEDE trial (MRC PR08, CRUK/06/019). Eur Urol. 2015;67(6):1028-38.

3. Metcalfe J, Smaldone C, Lin W, et al. Role of radical prostatectomy in metastatic prostate cancer: a review. Urol Oncol. 2017;35(4):12534. 
4. Hall D, Schultheiss E, Farino G. et al. Increase in higher risk prostate cancer cases following new screening recommendation by the US Preventive Services Task Force (USPSTF). Am Soc Clin Oncol. 2015;33:143.

5. Weiner A, Matulewicz R, Eggener S. et al. Increasing incidence of metastatic prostate cancer in the United States (2004-2013). Prostate Cancer Prostatic Dis. 2016;19(4):395.

6. Calais da Silva E, Bono V, Whelan $\mathrm{P}$, et al. Intermittent androgen deprivation for locally advanced and metastatic prostate cancer: results from a randomised phase 3 study of the South European Uroncological Group. Eur Urol 2009; 55: 1269-1277.

7. Wilke R, Parker C, Andonowski A, et al. Testosterone and erectile function recovery after radiotherapy and long-term androgen deprivation with luteinizing hormone-releasing hormone agonists. BJU Int. 2006; 97:963

8. Sweeney J, Chen H, Carducci M, et al. Chemohormonal therapy in metastatic hormone-sensitive prostate cancer. $N$ Engl $J$ Med. 2015;373:737-46.

9. James D, Sydes R, Clarke W, et al. STAMPEDE investigators. Addition of docetaxel, zoledronic acid, or both to first-line long-term hormone therapy in prostate cancer (STAMPEDE): survival results from an adaptive, multiarm, multistage, platform randomised controlled trial. Lancet. 2016;387:1163-77.

10. Fizazi K, Tran N, Fein L, et al. LATITUDE Investigators. Abiraterone plus prednisone in metastatic, castration-sensitive prostate cancer. N Engl J Med. 2017;377:352-60.

11. James D, de Bono S, Spears R, et al. STAMPEDE Investigators. Abiraterone for prostate cancer not previously treated with hormone therapy. N Engl J Med. 2017;377:33851
12. Amal I, Hussein $\mathrm{K}$, Nabiel M, et al. Cancer Incidence in Egypt: Results of the National Population - Based Cancer Registry Program Journal of Cancer Epidemiology.2014. Available at: https://www.hindawi.com/journals/jce/2014/437 $\underline{971 /}$

13. American Cancer Society. Cancer Facts \& Figures 2015. Atlanta: American Cancer Society. Available at:

https://www.cancer.org/research/cancer-factsstatistics/all-cancer-facts-figures/cancer-factsfigures-2015.html

14. Jemal A, Bray F, Center M, et al. Global cancer statistics. CA Cancer J Clin.2011;61: 69-90.

15. Xiao H, Tan F, Adunlin G, et al. Factors Associated with Overall Survival Prostate Cancer in Florida: A Multilevel Analysis. Journal of Health Care for the Poor and Underserved.2015;26(1): 266-77.

16. Sweeney C, Chen Y, Liu G, et al. Long term efficacy and QOL data of chemohormonal therapy in low and high volume hormone naïve metastatic prostate cancer: E3805 CHAARTED trial. Ann Oncol. 2016;27(suppl_6):243-65.

17. James $\mathrm{D}$, de Bono $\mathrm{S}$, Spears $\mathrm{R}$, et al. STAMPEDE Investigators. Abiraterone for prostate cancer not previously treated with hormone therapy. N Engl J Med. 2014;377:33851.

18. Hussain $M$, Tangen $M$, Berry $L$, et al. Intermittent versus continuous androgen deprivation in prostate cancer. $N$ Engl $\mathrm{J} \mathrm{Med}$. 2013; 368:1314-25.

19. Tannock F, Berthold R, Pond R, et al. Docetaxel plus prednisone or mitoxantrone plus prednisone for advanced prostate cancer: updated survival in the TAX 327 study. J. Clin. Oncol.2008; 26, 242-45. 